\title{
Technique of Fabrication of Definitive Hollow Obturator for Partial Maxillectomy Patient
}

\author{
${ }^{1}$ Manjita M Parab, ${ }^{2}$ Meena A Aras, ${ }^{3}$ Vidya Chitre
}

\begin{abstract}
Aim: Closed hollow obturators are often fabricated to provide adequate retention, stability and comfort for the patient.

Background: Rehabilitation of patient with maxillary obturator is the most common treatment option after maxillectomy. However, the heavy weight of obturator often leads to discomfort and problem in its retention.
\end{abstract}

Case report: This article presents rehabilitation of a patient after the surgical removal of desmoplastic ameloblastoma. It employs a simple procedure to create a closed hollow obturator with uniform and adequate thickness of prosthesis wall.

Conclusion: The technique offers advantage since it is easily fabricated with routinely used materials in a short time.

Keywords: Caramel spacer, Hollow obturators, Maxillary obturators, Maxillectomy.

How to cite this article: Parab MM, Aras MA, Chitre V. Technique of Fabrication of Definitive Hollow Obturator for Partial Maxillectomy Patient. Int J Prosthodont Restor Dent 2017;7(1):38-41.

Source of support: Nil

Conflict of interest: None

\section{INTRODUCTION}

Patients who have undergone maxillectomy as a result of carcinoma or facial trauma have facial disfigurement, i.e., associated with long-term psychosocial effects. Prosthetic rehabilitation of such patient becomes difficult due to numerous clinical and technical problems. ${ }^{1}$ Obturator prosthesis remains the treatment of choice over surgical reconstruction due to ease of fabrication and maintainance. ${ }^{2,3}$ The glossary of prosthodontic terms defines an obturator as "a maxillofacial prosthesis used to close a congenital or acquired tissue opening, primarily of the hard palate and/or contiguous alveolar/soft tissue structures." ${ }^{4}$ Treatment sequence includes placing of surgical obturator during the surgery followed by interim

\footnotetext{
${ }^{1}$ Postgraduate Student, ${ }^{2}$ Professor and Head, ${ }^{3}$ Professor

${ }^{1-3}$ Department of Prosthodontics, Goa Dental College and Hospital, Bambolim, Goa, India

Corresponding Author: Manjita M Parab, Postgraduate Student, Department of Prosthodontics, Goa Dental College and Hospital, Bambolim, Goa, India, Phone: +919762311906 e-mail: manjitaprb9@gmail.com
}

obturator during wound healing period, which is then replaced by definitive obturator after 3 to 6 months postsurgery. ${ }^{1}$ The definitive prosthesis fabricated should be easy to construct, lightweight, and should have good retention, support, and stability keeping in mind comfort of patient. ${ }^{5}$ Numerous techniques have been described in the literature for fabrication of hollow bulb obturators which can be open or closed obturators to reduce the weight of the prosthesis delievered..$^{6-8}$ The open hollow obturators are easy to fabricate but are difficult to maintain due to collection of moisture and debris, which leads to oral malodor and requires frequent cleaning. Hence, closed hollow obturators are preferred. However, the processing techniques are tedious and time consuming.

The processing technique described in this article is a single-stage, simple technique with an innovative material for creating hollow space. This article describes a technique for fabrication of definitive closed hollow obturator for a patient who had undergone partial maxillectomy secondary to desmoplastic ameloblastoma.

\section{CASE REPORT}

A 35-year-old female patient was referred to the Department of Prosthodontics, Goa Dental College and Hospital, India, for prosthetic rehabilitation after the surgical removal of desmoplastic ameloblastoma of right side of maxilla. Patient was wearing an interim prosthesis for last 6 months. Intraoral examination showed presence of healthy surgical site with caries-free left maxillary as well as mandibular dentition. There were no gingival or periodontal problems found in the remaining dentition. The patient complained of difficulty in chewing and speech and also nasal regurgitation of fluids. There was facial asymmetry due to depression in left malar prominence. The surgical defect was classified as class I defect according to Aramany's classification. ${ }^{9}$ A hollow obturator was planned as a definitive prosthesis for this case.

\section{Technique}

- The primary impression was made using irreversible hydrocolloid impression material (Vignette chromatic, Dentsply) by packing the defect area with gauze (Fig. 1).

- Following this, the cast was surveyed for designing of the cast partial denture framework. The framework 


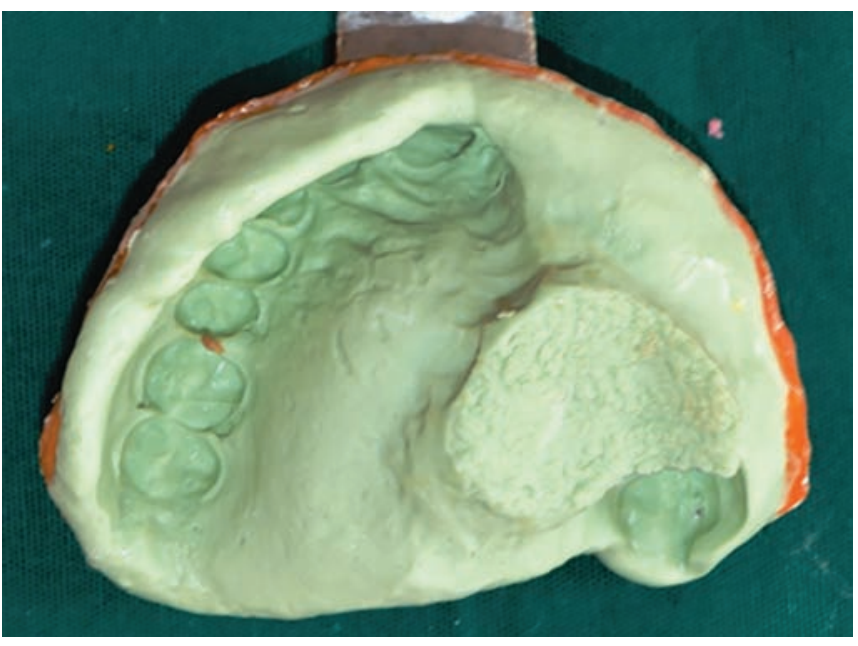

Fig. 1: Primary impression of defect area

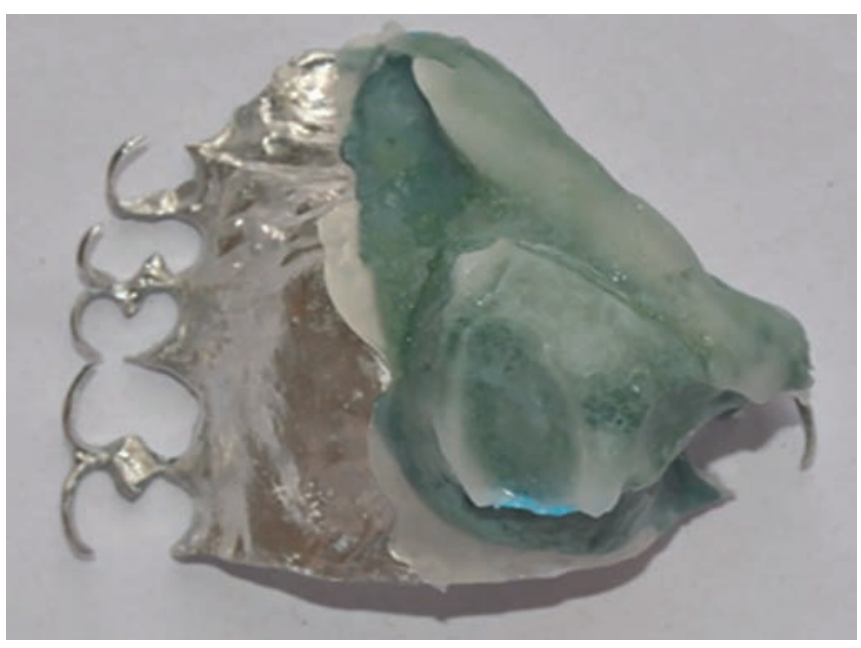

Fig. 3: Border molding and secondary impression

was designed such that maximum retention, stability, and support could be achieved using the dentition on the contralateral side.

- Mouth preparation was completed in subsequent appointment and recorded using elastomeric impression material (elite HD+, Zermack).

- After fabrication of cast metal framework, it was tried intraorally for evaluation of fit (Fig. 2). Selfcure acrylic tray (DPI-RR, Dental Products of India, Mumbai) was added on the defect region of the framework and the tray was verified intraorally to check for overextension.

- Following this, border molding was carried out and impression of the defect area was registered using greenstick compound. Wash impression of the defect area was made using tissue conditioner material (Visco-gel; Dentsply Ltd., Weybridge, UK) (Fig. 3).

- The master cast was made using altered cast technique. After obtaining the cast, record base was made using self-cure acrylic resin and an occlusal rim was fabricated.

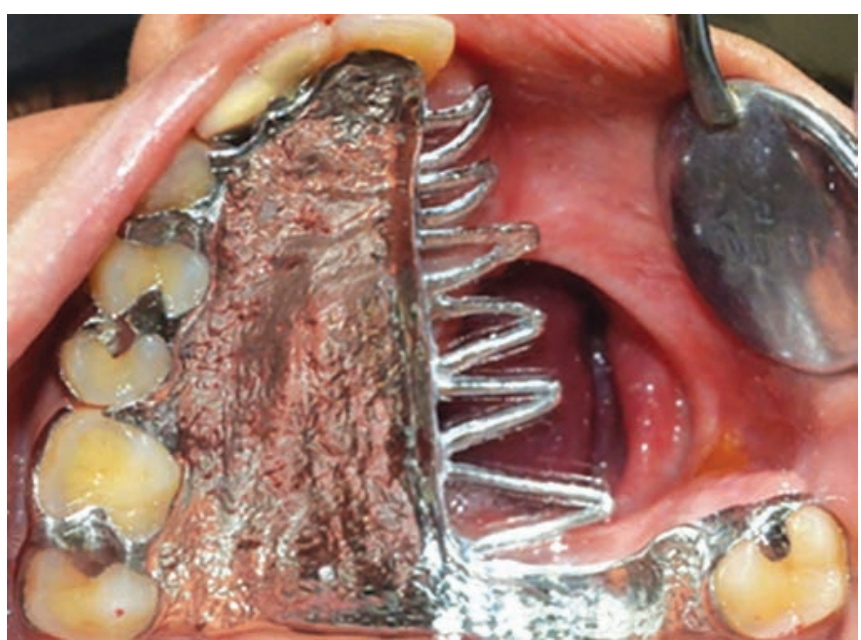

Fig. 2: Intraoral framework trial

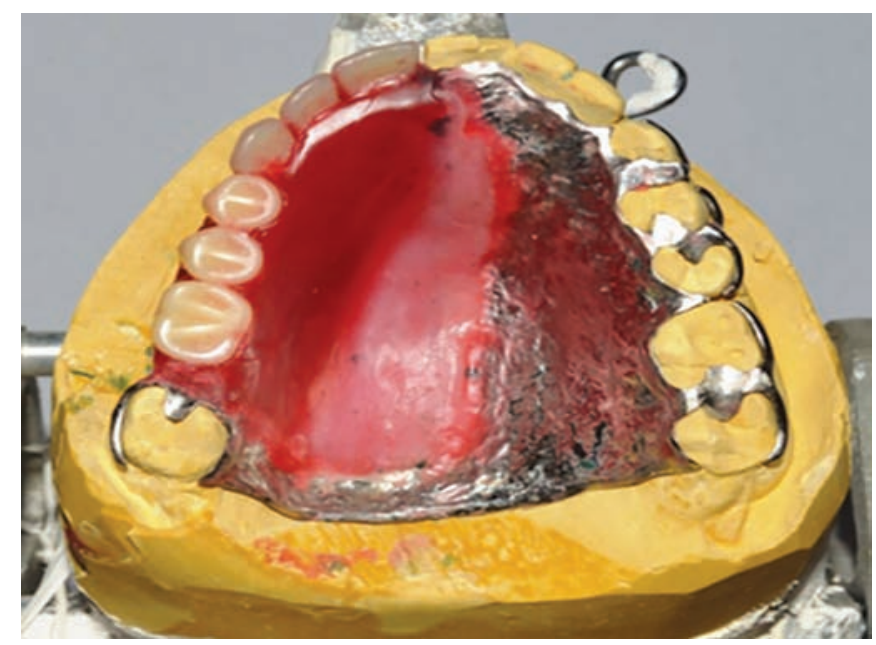

Fig. 4: Try-in done with monoplane dentition

- Jaw relation and try-in was done with monoplane dentition taking into consideration the esthetic and phonetic requirements (Fig. 4).

- Waxed-up trial denture was sealed to the master cast and invested in the flask.

- All components were covered with investing stone except the waxed-up part and the teeth during the first pour of plaster.

- After dewaxing, $2 \mathrm{~mm}$ of modeling wax (Deepti Dental Products) was adapted on two halves of the separated flask to ensure adequate and uniform thickness of acrylic resin around the future hollow cavity (Fig. 5).

- For achieving the hollow cavity, a temporary threedimensional spacer was fabricated first using putty consistency of an addition silicone impression material (Zeta Plus, Zhermac).

- To fabricate the final caramel spacer, a mold was created with the temporary putty spacer. Fifty milligrams of sugar was heated in a container on a flame for around 5 minutes till it is caramelized. 


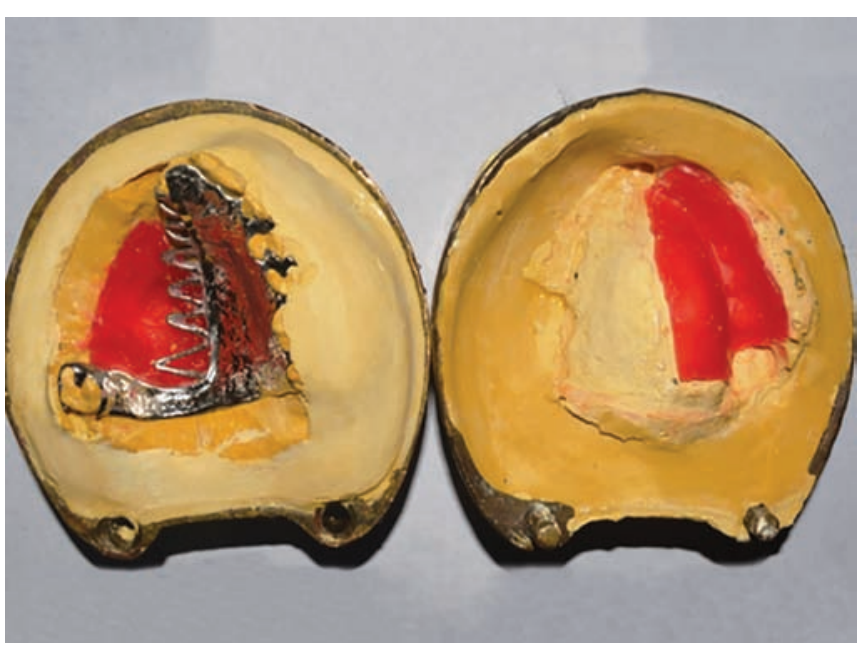

Fig. 5: Two layer modeling wax adapted to ensure uniform thickness of wax

- The caramel in the liquid stage was flown into the mold and left to harden for around 15 minutes. Caramel spacer obtained was evaluated for the contour and to check for any deficiency (Fig. 6).

- During trial closure, temporary putty spacer was used first; hollow space obtained was evaluated for accuracy of positioning of caramel spacer. The hollow space was then filled with caramel spacer and final closure performed.

- After acrylization, obturator was deflasked and finished in usual manner.

- Caramel spacer was retrieved by making a small opening in the palatal aspect of denture base and then placing it in warm water for around 15 to 20 minutes.

- The hollow cavity was air dried and sealed with autopolymerizing acrylic resin (Fig. 7).

- The obturator was finished, polished, and delivered to the patient (Figs $8 \mathrm{~A}$ and $\mathrm{B}$ ).

\section{DISCUSSION}

The article described a technique for fabrication of hollow obturator, i.e., new, simple, and economical and with less

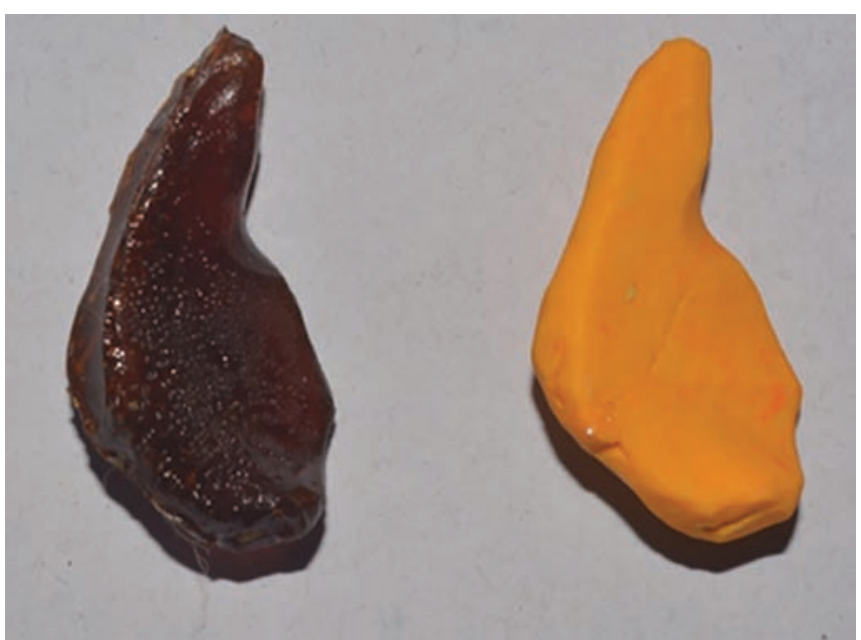

Fig. 6: Caramel spacer fabricated in accordance with putty spacer

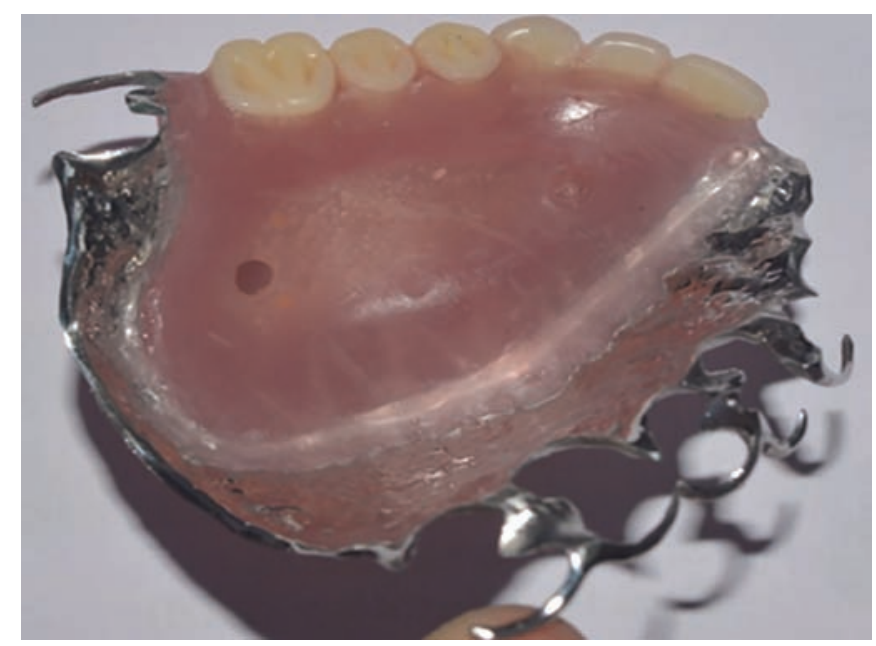

Fig. 7: Caramel spacer retrieved after acrylization with holes created on palatal aspects

time consumption. There have been numerous techniques described in the literature for creation of hollow obturator. Grinding out the unwanted part directly after processing described by Habib and Driscoll ${ }^{10}$ was once a classic technique. However, this technique is time consuming
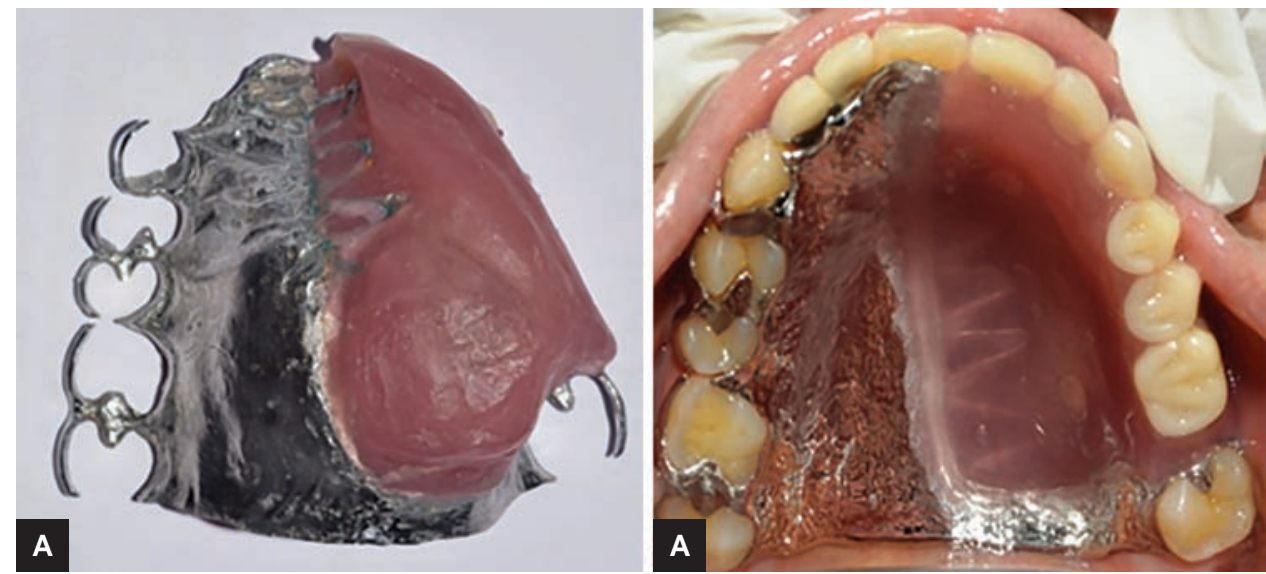

Figs 8A and B: Obturator finished, polished, and delivered 
and it is difficult to maintain the adequate and uniform thickness of the prosthesis wall. Also, techniques involving processing the obturator in two halves separately and later joining them together are described. ${ }^{11,12}$ These techniques are tedious, time consuming, require attachments, and are also difficult to repair.

The present technique is advantageous in many ways. It provides a predictable internal dimension of the hollow space since the hollow space is determined by the spacer used. This ensures uniform thickness of the obturator wall. Also, it is a one-step procedure wherein the obturator is made as a single unit.

Caramel spacer which has been modified in accordance with putty spacer before packing of the denture is used. Advantage of caramel spacer is easy retrievability with water agitation, sufficient rigidity to withstand force of packing, no effect on polymerization of heat cure acrylic, and no residues in the hollow prosthesis. Sine caramel is readily available and there is no inclusion of any attachments, the technique is economical.

\section{CLINICAL SIGNIFICANCE}

The article presents a unique method of creating a closed hollow maxillary obturator using a single-flask method, i.e., quite easy to fabricate, requires less laboratory time, is inexpensive, and uses caramel for creation of hollow space that is easily retrievable.

\section{REFERENCES}

1. Beumer J, Curtis T, Marunick M. Maxillofacial rehabilitation: prosthodontic and surgical considerations. St. Louis (MO): Ishiyaku EuroAmerica; 1996. p. 240-285.

2. Rieger J, Wolfaardt J, Seikaly H, Jha N. Speech outcomes in patients rehabilitated with maxillary obturator prostheses after maxillectomy: a prospective study. Int J Prosthodont 2002 Mar-Apr;15(2):139-144.

3. Pigno MA. Conventional prosthetic rehabilitation after free flap reconstruction of a maxillectomy defect: a clinical report. J Prosthet Dent 2001 Dec;86(6):578-581.

4. The glossary of prosthodontic terms. J Prosthet Dent 2005 Jul;94(1):10-92.

5. $\mathrm{Wu} Y \mathrm{~L}$, Schaaf NG. Comparison of weight reduction in different designs of solid and hollow obturator prostheses. J Prosthet Dent 1989 Aug;60(2):214-217.

6. Shaker KT. A simplified technique for construction of an interim obturator for a bilateral total maxillectomy defect. Int J Prosthodont 2000 Mar-Apr;13(2):166-168.

7. Patil P, Patil S. A hollow definitive obturator fabrication technique for management of partial maxillectomy. J Adv Prosthodont 2012 Nov;4(4):248-253.

8. Deogade SC, Mantri SS, Naitam D, Dube G, Gupta P, Dewangan A. A direct investment method of closed two-piece hollow bulb obturator. Case Rep Dent 2013;2013:326530.

9. Aramany MA. Basic principles of obturator design for partially edentulous patients. Part I: classification. J Prosthet Dent 1978 Nov;40(5):554-557.

10. Habib BH, Driscoll CF. Fabrication of a closed hollow obturator. J Prosthet Dent 2004 Apr;91(4):383-385.

11. Browning JD, Kinderknecht J. Fabrication of a hollow obturator with fluid resin. J Prosthet Dent 1984 Dec;52(6):891-895.

12. Elangovan S, Loibi E. Two-piece hollow bulb obturator. Indian J Dent Res 2011 May-Jun;22(3):486-488. 